\title{
The Experiences of Elderly People Living at Home Related to Their Receiving Meals Distributed by a Municipality in Sweden
}

\author{
Zada Pajalic (Corresponding author) \\ School of Health and Society, Kristianstad University \\ Elmetorpsvägen 15, Kristianstad 29188, Sweden \\ \& \\ School of Medical and Health Sciences \\ Örebro University, Örebro 70182, Sweden \\ E-mail: zada.pajalic@hkr.se \\ Lena Persson \\ School of Health and Society, Kristianstad University \\ Elmetorpsvägen 15, Kristianstad 29188, Sweden \\ E-mail: lena.person@hkr.se \\ Albert Westergren \\ School of Health and Society, Kristianstad University \\ Elmetorpsvägen 15, Kristianstad 29188, Sweden \\ E-mail: albert.westergren@hkr.se \\ Berggren Vanja \\ School of Health and Society, Kristianstad University \\ Elmetorpsvägen 15, Kristianstad 29188, Sweden \\ E-mail: vanja.bergren@hkr.se \\ Kirsti Skovdahl \\ School of Medical and Health Sciences \\ Örebro University, Örebro 701 82, Sweden \\ E-mail: kirsti.skovdahl@oru.se
}

$\begin{array}{ll}\text { Received: December 16, } 2011 & \text { Accepted: January 5, } 2012 \quad \text { Published: February 1, } 2012 \\ \text { doi:10.5539/jfr.v1n1p68 } & \text { URL: http://dx.doi.org/10.5539/jfr.v1n1p68 }\end{array}$

The study was funded by Kristianstad University and Skåne County Council. Sweden.

\begin{abstract}
The purpose of the study was to describe the experiences of elderly people, living at home who receive hot meals that are distributed by their municipality. Qualitative content analysis was used to analyse the $(n=13)$ interviews. The results showed that feelings of dependency, loneliness and gratitude were expressed by the participants in the study related to their meals being delivered home. Dependency was expressed as not having influence over the food products the meals were made from. Loneliness was expressed as being isolated and being confined at
\end{abstract}


home alone due to difficulties getting out of the house, which was associated with the costs of taxis transportation. Gratitude was expressed by the sincere thanks for the possibility of receiving traditional meals delivered daily.

The major conclusion of the study was the indication that greater attention should be paid to meet both the practical and psychological needs of elderly people.

Keywords: Action research, Elderly people, Distribution of meals, Home-living

\section{Introduction}

In Sweden the "Food Distribution" (FD) system of meal distribution which may be compared to the international concept of "meals on wheels", is a service offering prepared meals delivered to elderly people or persons with health related impairments who live in their own home. The FD in Sweden is a social and care service assistance system organised by a municipality in accordance with the Swedish Social Services Act (Grönwall \& Holgersson, 1998).

Swedish municipalities have the statutory obligation to provide social and care service assistance and this is regulated by two laws: the Social Services Act (Grönwall \& Holgersson, 1998) and the Health and Medical Services Act (Raadu, 2011). Neither of these laws have detailed information about how FD should be organised, which allows each municipality to organise their FD services according to its own circumstances (Rothenberg \& Lewald, 2006). For a person to be granted the FD service from any municipality, an assessment of the individual's requirements has to be made by community officers.

The fundamental requirement for being granted FD is that the individual is unable to do their own shopping and prepare their own meals, and the foremost reasons for this situation are illness related physical or psychical limitations (Grönwall \& Holgersson, 1998). The number of elderly persons ( $\geq 65$ years), in Sweden, receiving food distributed by municipally organised FD is estimated at 60,000 . The requirement for this service is expected to increase in the future (Statistical Central Office, 2009).

The organisation of FD in Sweden differs from that in other welfare states where the FD, is mostly organised by either private companies or voluntary organisations, Examples of this are the USA (Frongillo et al., 2010), the UK (McKie, Clark, MacLellan, \& Skerratt, 1998), Canada (Timonen \& O'Dwyer, 2010), Australia (Krassie \& Smart, 2000), Germany (Sneeuw, Stam, de Graaf, \& van Staveren, 1991), Japan (Nakura, Tatara, Shinsho, Fukuda, \& Nakajima, 1994), The Netherlands (Aagaard Nielsen \& Svensson, 2006), France (Michaud et al., 1998) and Italy (Inelmen et al., 2000). In most of these countries the charges for all care and services are related to the client's income/pension. In some countries, such as Finland, the UK, Germany and France, those who cannot pay are referred to the state social assistance system. In The UK, Germany and Spain the receivers of all care and services pay $20-30 \%$ of the total cost. The fee for FD in Sweden is regulated and is based on the elderly person's ability to pay, however they pay a maximum of $10 \%$ of the total cost (Elmér, 2000).

To date, research focusing on elderly people's experiences related to food and eating hasmainly been concerned with eating as seen from a social and cultural perspective (Sidenvall, 1995). There are studies showing that meals-on-wheels receivers are at risk of malnutrition (Coulston, Craig, \& Voss, 1996; Johansson, Bachrach-Lindstrom, Carstensen, \& Ek, 2009; Payette, Boutier, Coulombe, \& Gray-Donald, 2002). Other studies show that FD is an important service but that the consumer's experience of the service and products depends upon a range of factors including nutritional status (Krassie \& Smart, 2000; Roberts, Wolfson, \& Payette, 2007), demographic and socio-economic factors, and menus that accommodate the individual consumers' requirements and preferences. This highlights the importance of assessing the consumers' experiences in order to improve the FD services (Almanza, Namkung, Ismail, \& Nelson, 2007; Krassie \& Smart, 2000). Elderly people who receive their meals distributed through an FD service have important experiences and knowledge to share that can be used for improving the FD service (Gustafsson, Ekblad, \& Sidenvall, 2005; L. Johansson, Sidenvall, Malmberg, \& Christensson, 2009). However, there is, a lack of studies focusing on elderly people's experiences of receiving meals distributed by a municipality. This knowledge is of importance in order to provide and ensure the high-quality of the FD services and that the services meet the client's individual requirements.

\section{Aim}

The purpose of the study was to gain insight into, and describe the experiences of elderly people, living at home who receive hot meals that are distributed from the municipality. 


\section{Research Method}

This qualitative, descriptive study is a part of larger research project using an action research (AR) approach (Bondas, 2003; Meyer, 1993; Stringer \& Genat, 2004) focusing on meal distribution to elderly persons ( $\geq 65$ years) living at home.

\subsection{The context}

The project was conducted in a medium-sized municipality of about 80,000 inhabitants situated in southern Sweden. Approximately 650 elderly people living in the municipality used the FD service, but this number varied over the weeks as some pensioners only used the FD service on some days of the week. The meals were produced at a municipally owned kitchen. The menu consisted of two hot dishes each day and an extraordinary meal once a month. The most common meal delivered was lunch, which corresponded to $30 \%$ of the clients' daily nutritional needs. The possibility to also have evening meals delivered did exist, but was not commonly used. The lunch also included raw vegetables and fruit or dessert all inclusive. Assistant nurses or taxi drivers were responsible for the transportation and delivery of the meals. The meal box was supposed to be delivered personally to the customer, that is to say "into their hands", and not simply left outside their door.

\subsection{Study participants}

The inclusion criteria for the participants in the study were that the informants should be aged $\geq 65$ years, receiving FD, living in their ordinary home, and able to communicate verbally in Swedish. During July 2009 an information letter about the study and a request for informed consent and an addressed reply envelope was sent, with a meal box delivery, to all those persons who met the inclusion criteria. Those elderly persons who agreed to participate in the study replied, giving their informed consent and information noting when they wished to be contacted by the first author (ZP). Thirteen elderly persons agreed to participate in the study: three men aged between 75 and 92 years (average 83.5 years) and ten women aged between 68 and 89 years (average 78.5 years). All were living alone and received meals from the FD service delivered either by assistant nurses $(\mathrm{n}=9)$ or by taxi drivers $(\mathrm{n}=3)$.

\subsection{Data collection}

Individual semi-structured interviews were conducted (Kvale, 2007). The interviews began with the interviewer encouraging the participants to talk about what they felt was important relating to their receiving meals distributed by the municipality and what were their experiences of the service. The interviews were conducted, by the first author (ZP), in the homes of the participants, during September-December 2009, and each lasted about 45 to 60 minutes. The interviews were tape-recorded and transcribed verbatim.

\subsection{Analysis process}

Manifest and latent qualitative content analysis (Graneheim \& Lundman, 2004) was used to analyse the interviews. The transcripts were read by authors (ZP, VB \& AW) as openly as possible to gain a sense of the whole and to get ideas for the further analysis with the study aim as a basis. Meaning units were identified and condensed into codes. A manifest analysis was used to describe that which was obvious and visible in the text. Next, a latent analysis was used to grasp deeper meaning in the text. Questions related to what the text was talking about and what this meant were "addressed to the text" in order to reveal the deeper structural meaning. The latent analysis consisted of dialectical movements between the whole and the parts, between understanding and explanation and between explanation and comprehension. The codes were critically reflected on and compared in relation to the research question and sorted into categories and one theme. Lastly, all authors reflected and discussed the findings in relation to the research question and were agreed concerning the final interpretation of the theme and categories. A main theme "The meal box as a symbol of feeling dependent and lonely but grateful" arose from three categories: "Being dependent but able to exert influence on a small scale", "Feeling lonely" and "Feeling grateful"

\subsection{Ethical considerations}

The study was performed in accordance with the World Medical Association Declaration of Helsinki (Saif, 2000) and has been examined by the regional ethical review board (LU09/365). All the participants received written information explaining the nature of the study, what was required of them, that their participation was voluntary, and that they had the right to end their participation at any time without any consequences for them. When the participants gave their informed consent to participate in the study the first author contacted them and booked a time and place for the interview. The information given earlier about the purpose of the study, voluntary participation, the right to withdraw from participation in any interview at any time, without any consequences for them, was given to the participants again, verbally, before each interview. 


\section{Results}

\subsection{The meal box as a symbol of feeling dependent and lonely but grateful}

The participant's experiences of receiving meals from the FD were interpreted as interplay between mental, social, emotional and existential needs. Feelings of dependency and loneliness were expressed by the elderly in relation to the timing of the delivery of their meals, as this could vary about one hour from day to day. Dependency could also be interpreted in situations when the elderly felt they had no influence over the food products from which the meals were made or the type of the fruit delivered with the meal. For instance, some participants wanted fruit that was easy to chew and digest, like melon, grapes or bananas etc, rather than hard fruit such as apples and in some cases pears. If hard fruit was served, the possibility to have it grated should be offered. Loneliness was interpreted from situations where the elderly described their involuntary isolation due to their being confined to their home; where they found themselves physically and economically prevented from breaking their isolation; or when they felt insecure and dissatisfied with life. Gratitude was described in terms of; the possibility to choose between two different menu alternatives and their variety; daily delivery of fresh and newly prepared hot meals with the possibility to cancel the meal service when they were not at home.

\subsection{Being dependent but able to exert influence on a small scale}

The experience of being dependent but still able to actively influence food-related activities

was described by the participants in different ways. They knew that they had the possibility to influence, despite their being dependent and they put this possibility into practice by personally planning and writing a grocery list, choosing the dishes on the menu, and participating in meal distribution evaluation surveys. A central indication in all of the interviews with the participants was that their feeling of being active made a difference to them even in their otherwise dependent position, which in turn helped to increase their self-esteem.

\section{"I have written a list of dishes that I would like to have on the menu..."}

Having the possibility to choose meal menus they preferred was valued highly by the participants. From the menu, they had the possibility to choose between two dishes, and of these two, the traditional food was often the most popular. The participants noted that it was difficult to accept that they could not themselves handle food preparation activities in the same way as before. For them, the decrease in their bodily functions and the development of dependency came gradually, for instance, after injuries, caused by dizziness, decreased optical function or difficulty with their sense of balance. It appeared that changes or losses in physical function were hard to accept as they now found that they had to accept help. The study results indicated that dependency on others in connection with food related activities were also associated with the participant's personal privacy. Therefore, it was a difficult experience for the participants to be forced to accept help from strangers, often in the form of the various professionals involved in public home care.

"From the beginning I refused to eat but now I have agreed to do so. I used not to feel comfortable with the staff but now I am pleased with them. It feels horrible to have strangers in your own home when you are old and helpless."

The findings in the study indicated that the participants needed time to learn to accept being dependent on help and that acceptance appears to be a process in which they began by refusing the possibility of delivered meals, but accepted them after a while. The participants noted that they felt positive about being relieved of having to shop and prepare food at home. One male participant noted that he felt he had a better life since he began receiving his meals, at home through the $\mathrm{FD}$, and went on to say that this was due to the fact that he no longer needed to spend his energy preparing his meals. From the statement above it would appear that some participants accepted the help offered by the meal service if it meant their not having to deal with practical issues, such as having to prepare their own meals.

Another experience that was noted by the participants was their reflection on life. One woman said that she had finally accepted help through the FD system and that she considered that this was a part of life's cycle. Food and food-related activities were experienced by the participants as some kind of action or technique aimed at giving them energy. This indicated that food was eaten simply for the sake of eating, to fend off hunger rather than, for enjoyment and sensation. Some participants said that they do not like all the dishes but they tried to eat them anyway if only for the nutritional value.

"When I get food in the meal boxes that I do not like to eat, I still try to force it down, most of the time."

The participants expressed that the fact that they were not able to influence the time of the day that the meals were delivered made it difficult for them. Sometimes their meal was delivered too early or too late for them. 
They said that the taxi drivers only delivered the meal and then left. On the other hand, there were the assistant nurses who always asked if they could help by opening the meal box or putting the food on a plate. Some of the women participants spoke of the importance of meal time situations being treated as an entirety. For this reason they felt it was important that they were asked if they needed help to put the food on a plate.

"At first when I got food delivered it came around 11.30, but now it is almost 12.35, the assistant nurses are usually more on time than the taxi drivers are."

Some of the participants offered suggestions for how the service could be improved, based on their personal experiences. For example "proper food" should be prepared from natural products and not from semi-manufactured food products. According to their experience the food from institutional kitchens could well taste like home-cooked food since it was based on natural food products. They further noted that for those people who have problems with their teeth alternative types of fruit should be offered, for example soft and hard fruits with the choice of having the hard fruits grated.

"Apples and pears should be soft or grated into smaller pieces, because if I take a wrong bite my teeth will fall out."

4.3 Feeling lonely

The participant's narratives dealt with several aspects of the meal box as a symbol of their dependency in relation to their being isolated or alone in their home and their having feelings of sorrow and insecurity. They further described how loneliness was connected to their involuntary isolation in their home due to difficulties in getting around as they would wish which was due to financial restraints. All the activities they would like to do, such as shopping, meeting other people or eating at restaurants, were associated with additional costs. Regarding these limitations, the participants noted that they needed taxi transportation to get to the nearest store. They further noted that shopping activities gave them the possibility to meet other people which helped them fulfil their social needs even though such meetings were often short hopping by themselves and also gave them the opportunity to see "first hand" the articles they might wish to purchase, Taxi transportation entailed extra costs which they had difficulty in affording. The participants expressed how they felt sad about their loss of ability to shop for food by themselves, to keep updated with new products, and to eat together with significant others.

"Since last September I was honestly quite out of my mind, since I put my dogs to sleep when I had to stay at the hospital for three months and then when I came home I ate alone. I couldn't talk to the kitchen walls. I have no living relatives."

Feelings of sorrow were emphasised even more by elderly people whose family members had died. One of the participants described how some dishes reminded her of her late daughter who had been disabled. As a mother she had cared for her daughter, among other ways by cooking her favourite meals.

"I loved to cook and my favourite was cabbage soup that I made for my daughter who was disabled."

Or as one participant, a widower put it: "It feels terrible to eat alone; I can't even talk about it."

When the category loneliness was reflected upon it seemed that this was also connected to feelings of insecurity, discomfort with a new situation, and the fact that the participants did not know who they should contact if they had any questions. Their narratives also expressed their feelings of being exposed if they should be confronted with difficulties due to having insufficient information from the professionals responsible for the distribution of meals, or from the taxi drivers. Some of the elderly spoke about difficulties accepting that the taxi drivers were unable to answer their questions concerning meal distribution. It appeared that the participants tried to convey the message that they should not have to continually ask for service, or as one participant described her communication with a taxi driver

"Last month I didn't get any fresh fruit so I asked him if he had any fruits or vegetables for me to which he replied "no" so I complained to him every single day"

The participants also described loneliness in the context of the symbolic value of the meals as being something important and essential in their lives. For them, this was the first time since their childhood that they became dependent on others for help and they did not find it easy to articulate their feelings of despondency that this situation brought about. It appeared as if some of their independence had been lost as a result of receiving this kind of help. Women especially, who traditionally had the responsibility for food-related tasks for their families, expressed such feelings of despondency. Earlier, social status had influenced the participant's views on loneliness, much depending on whether they earlier had a partner or not. It seems that those among the participants who had lived alone, when they were younger, did not experience being alone as something negative. 
The participants used different strategies to compensate for their social needs related to meal times, such as visiting day-centres, simply accepting that they were alone, or watching television or listening to the radio.

"I have no problems eating alone because I can take my time and enjoy the food as long as it is good, no matter whether I am alone or I have company."

\subsection{Feeling grateful}

The participants expressed their sincere gratitude for the meal service they received from the municipality. All of them noted that they were well aware that food was essential for their health. They described the meals they received through the FD as being varied, healthy and a good alternative to home-cooked food. They found the FD food tasty. They also thought the food was worth the price, especially since a dessert and raw vegetables were also included in the price. Some felt that the portions were too large and that they sometimes split the delivery into two meals. Saving food and feeling a sense of gratitude for having their meals delivered to their home was something crucial for them. This was something that they had learnt during their lifetime.

"I think my life is good in terms of the service I get from the municipality.

From the participants perspective, it was an advantage to have the possibility to choose their

meals from a menu, and they compared the food distribution services between different

municipalities from information they could find in the media. Based on the information they had, the majority of them were grateful for the daily delivery of hot meals rather than the weekly delivery of frozen meals. It seemed that many of the participants greatly valued the

possibility to receive one or two hot meals every day, since they had heard that elderly people in other municipalities received only frozen food. They expressed negative views about the idea of only receiving frozen or cold food once a week and called this a "punishment". Furthermore, the possibility to cancel meal deliveries, when they were away, was appreciated as this meant that they could freely plan their time. It was also obvious that the participants had seen positive changes in the organisation of meal deliveries, which had resulted in a better service that was based on their input, such as the request for specific dishes on their menus. According to the participants, traditional food was most appreciated and regarded by them as "proper food".

"Some dishes I don't like but that's life."

It seemed that the variation in menus was considered as positive.

"I think that variation is good and I could not have come up with more variation myself."

\section{Discussion}

\subsection{Methodological considerations}

The purpose of the study was to gain insight into, and describe elderly people's experiences of receiving food distributed from the municipality. The experiences related by the participants in the study indicated that they were, in general, satisfied with the FD system from their municipality. As participation in the study was voluntary there is a risk that people receiving meal distribution, but who, at the same time are dissatisfied, were missed in the sample. If and how such experiences affected the findings remains unanswered in this study. Findings from the study can be evaluated in terms of trustworthiness: credibility, dependability, conformability and transferability (Lincoln \& Guba, 1985). Credibility was assured by presenting views from different participants in order to capture the different experiences, and by the fact that the co-authors were involved in the analysis. Dependability was assured by the fact that the same researcher, the first author ZP, carried out all the interviews and transcriptions. The use of a tape-recorder and verbatim transcripts, as well as referring back to, and rereading the transcripts during the analysis process, allowed the researchers to remain close to the text. The citations make it possible to assure conformability. Transferability can be considered to have been achieved if the present results can be recognised and transferred to comparable contexts (Lincoln \& Guba, 1985)

\subsection{Discussion of the findings}

The study indicates that the meal box was experienced by the elderly persons participating in the study as a symbol of dependency and loss of identity as it became evident to them that they could no longer manage to shop and prepare hot food by themselves. Feelings of loneliness were reinforced when the participants did not know who to contact if they had questions about the municipal meal distribution service. Walker and Beauchene (1991) described that, for elder people, loneliness related to meals in the context of a social event was a result of sparse contact with their children and/or the loss of their spouse (Walker \& Beauchene, 1991). Further, that the 
feeling of loneliness is common even when people have others around them. This is due to the fact that it is important for a person to personally choose their company (Åhgren, 2003).

Involuntary loneliness is most often caused by widowhood (Hughes, Bennett, \& Hetherington, 2004), while voluntary isolation is a common strategy to avoid feelings of being observed by others when eating (Walker \& Beauchene, 1991). Aberg et al. (2005) showed that elderly people have different strategies for maintaining life satisfaction in relation to the care and social services. One strategy is to try to be active and independent. In situations they could not influence, elderly people used mental activities as an adaptation strategy, such as by recalling past memories in an effort to achieve a sense of satisfaction with their life. This strategy was described as having a potential risk for passive concealment of the dissatisfaction they felt with their current conditions (Aberg, Sidenvall, Hepworth, O'Reilly, \& Lithell, 2005). The results from this study confirms other studies that show that elderly people express a high level of understanding of the dangers of becoming introverted, alone and depressed (de Jong-Gierveld, Kamphuis, \& Dykstra, 1987). The FD services should focus on individual needs, and this implies that meals should be seen as a social event, a symbol of a good life.

Further, it was shown in a study by Odencrants, Ehnfors and Grobe (2005) that solitude was sometimes chosen actively as some elderly people felt as if they were being observed while they were eating and found it hard to follow new socio-cultural codes (Odencrants, Ehnfors, \& Grobe, 2005). Another study showed that elderly people chose to eat alone because they do not feel comfortable having company during meals they had not chosen freely, for example in the presence of assistant nurses (Leppänen, 2008). It is not unusual that many people choose some form of media as artificial company during meals (Sobal \& Nelson, 2003). Chosen or enforced loneliness at mealtimes was identified as a risk factor as it is related to inadequate food intake and less variety of food which can eventually lead to low food intake (Hughes, et al., 2004).

Findings in this study also indicated that it took time for the elderly participants to accept FD as they appeared to convey that they had an inner struggle with themselves over whether or not to accept the service. This can be interpreted as an adaptation to their new life situation (Kallio, Koskinen, \& Prattala, 2008). This is confirmed by similar findings that describe the process of being dependent on care as being a transformed relationship to oneself and others, adapting to a new situation, experiencing obstacles and opportunities along the way towards dependence (Locher et al., 2005). Being old and dependent, illustrated here in the form of a meal box; is a part of the life cycle and something that can take time to accept. The life cycle was conceptualised by Meleis (Meleis, 2010) as transitions which entail searching for meaning in new situations. The transitions denote a change in life, in physical and psychological health status, and new roles in a socio-cultural context. The transitions associated with health/illness can be accompanied by existential struggles related to identity as they require the individual to modify their behaviour.

This depends on an individual's values, beliefs, expectations and feelings about their situation (Andersson \& Sidenvall, 2001). The results of this study agree with another study by them that found that great emphasis is placed on the importance of having and showing interest in things and not vegetating (Andersson \& Sidenvall, 2001; Sidenvall, 1997). Throughout their life, people go through several transitions between the different phases of life, including the ageing process (McKie, MacInnes, Hendry, Donald, \& Peace, 2000). One example is the transition from being independent to being dependent on help from outsiders, which can be hard to manage, and this appears to correspond to the way that the elderly people in this study reasoned.

The individual opportunity to influence and negotiate dependency on care seems to limit the negative sense of being dependent (Rochat et al., 2010). This indicates that it is important to involve elderly people in the whole process, from the assessment of their needs to the decision about their receiving meal boxes. In earlier studies, being in need for support or help from other people for meals has been described as being phased out as a human being (Bülow et al., 2007). Being dependent on others can cause feelings of shame for the dependent person (Hayder \& Schnepp, 2008). Such feelings arise as result of a sense of being inferior, a burden, having low self-esteem and low self-confidence. Receiving meals through the FD seemed to be harder for women to accept possibly due to their traditional responsibility for preparing food for their family. Other reasons for these feelings can have a historical background, as today's elderly people grew up with norms and values requiring them to participate in the activities of daily living and to not be a burden on anyone (Gustafsson, Andersson, Andersson, Fjellstrom, \& Sidenvall, 2003). However the participants in this study noted that they felt increased self-esteem when they had the possibility to exert influence, even on a small scale, such as the possibility to choose their meals from a menu.

The participants in this study expressed sincere gratitude for the hot prepared meals they received on a daily basis from the municipality. The participants relation to food was rooted in their childhood and was guided by 
experiences gained throughout their life, for example, in terms of access to food, culture, religion, and the cost and quality of food (Maynard et al., 2006). This indicates that it is crucial to note and respect those elderly people, who live in their own homes, as individuals with their personal socio-cultural history, as this may have an important influence on how they experience their current life situation. It is confirmed by the findings in another study that described how many elderly people had witnessed massive changes in their lifetime, such as those in food production, access to, and the cost of food, besides having experienced a substantial change in their financial situation when leaving working life and becoming a pensioner (Sidenvall, 1995).

The results of this study showed that the participants were sincerely grateful for the FD service. This gratitude could have its roots in their experiences of the years of hardship and economic depression between the world wars and might be the reason why many elderly believe that food is a gift from God, that it should not be wasted, and that food is something to be grateful for (Meinow, Kåreholt, \& Lagergren, 2005). Family morality had instilled into them the norm of being grateful for the food they received, and it was not acceptable for them to say that they did not like some types of food (Sidenvall, Fjellstrom, \& Ek, 1994). Viewed from a social constructivist perspective, the elderly people who participated in this study created and formed social collective actions in their interactive exchange with others. These actions are based on the socially accepted cultural norms within the society they are part of, and although they may differ from individual to individual, they still provide an overall common collective picture (Burr, 2003).

\section{Conclusion}

This study indicates that greater attention needs to be paid to the experiences and views of elderly people who live in their own home, related to their receiving meals supplied by their municipality. Their experiences indicated that food distribution should not be seen as a fragmentary social support but as a starting point for empowering elderly people in order to prevent them having growing feelings of dependency and loneliness. This study shows that the meals distributed by the municipality have a symbolic value for the elderly. The professionals involved in FD can use the knowledge gained from this study to develop and improve their encounters with FD recipients. However, this study also reveals the need for further studies focusing on problems experienced by FD recipients.

\section{Acknowledgements}

We are grateful to all of the participants for their interesting input and inspiring dialogue. Thanks also to Karin Pettersson and the Kristianstad Municipality for welcoming this research.

\section{Relevance to Practice}

This study indicates that greater attention needs to be paid towards meeting both the practical and psychological needs of elderly people. Food distribution should not be seen as a fragmentary social support but as a starting point towards breaking the elderly's social isolation and to actively involve them in decision making in order to prevent them having feelings of dependency and loneliness. Furthermore, the FD organisation should be continuously improved towards offering an individually adapted service.

\section{References}

Aagaard Nielsen, K., \& Svensson, L. (2006). Action and interactive research : beyond practice and theory. Maastricht: Shaker Publishing.

Aberg, A. C., Sidenvall, B., Hepworth, M., O'Reilly, K., \& Lithell, H. (2005). On loss of activity and independence, adaptation improves life satisfaction in old age--a qualitative study of patients' perceptions. Qualitative Life Reserach, 14(4), 1111-1125.

Almanza, B. A., Namkung, Y., Ismail, J. A., \& Nelson, D. C. (2007). Clients' safe food-handling knowledge and risk behavior in a home-delivered meal program. $J$ Am Diet Assoc, 107(5), 816-821. http://dx.doi.org/10.1016/j.jada.2007.02.043

Andersson, I., \& Sidenvall, B. (2001). Case studies of food shopping, cooking and eating habits in older women with Parkinson's disease. Journal of Advanced Nursing, 35(1), 69-78. http://dx.doi.org/10.1046/j.1365-2648.2001.01823.x

Bondas, T. E. (2003). Caritative leadership. Ministering to the patients. Nursing Administration Quarterly, 27(3), 249-253.

Burr, V. (2003). Social constructionism. London: Routledge. 
Bülow, M., Camper, A. M., Ekman, S., Rothenberg, E., Sjöberg, K., Willén, E., et al. (2007). Elderly people needs in relation to food, nutrition and mealtime situations (in Swedish: Äldres behov i relation till mat, näring och måltidssituationer): SIK - the Swedish Institute for Food and Biotechnology.

Coulston, A. M., Craig, L., \& Voss, A. C. (1996). Meals-on-wheels applicants are a population at risk for poor nutritional status. Journal of the American Dietetic Association, 96(6), 570-573. http://dx.doi.org/10.1016/S0002-8223(96)00157-5

De Jong-Gierveld, J., Kamphuis, F., \& Dykstra, P. (1987). Old and lonely? Comprehensive Gerontology, 1(1), 13-17.

Elmér, Å. (2000). Swedish social politics (in Swedish: Svensk socialpolitik). Lund: Studentlitteratur.

Frongillo, E. A., Cantor, M. H., MacMillan, T., Issacman, T. D., Sherrow, R., Henry, M., et al. (2010). Who are the recipients of Meals-on-Wheels in New York City?: a profile of based on a representative sample of Meals-on-Wheels recipients, part I reprinted and adapted for the Care Management Journals with permission from Citymeals-on-Wheels. Care Management Journals, 11(1), 19-40. http://dx.doi.org/10.1891/1521-0987.11.1.19

Graneheim, U. H., \& Lundman, B. (2004). Qualitative content analysis in nursing research: concepts, procedures and measures to achieve trustworthiness. Nurse Education Today, 24(2), 105-112. http://dx.doi.org/10.1016/j.nedt.2003.10.001

Grönwall, L., \& Holgersson, L. (1998). 1998 års socialtjänstlag : med kommentarer. Stockholm: Gothia.

Gustafsson, K., Andersson, I., Andersson, J., Fjellstrom, C., \& Sidenvall, B. (2003). Older women's perceptions of independence versus dependence in food-related work. Public Health Nursing, 20(3), 237-247. http://dx.doi.org/10.1046/j.0737-1209.2003.20311.x

Gustafsson, K., Ekblad, J., \& Sidenvall, B. (2005). Older women and dietary advice: occurrence, comprehension and compliance. Journal of Human Nutrition Dietetics, 18(6), 453-460. http://dx.doi.org/10.1111/j.1365-277X.2005.00652.x

Hayder, D., \& Schnepp, W. (2008). Urinary incontinence - the family caregivers' perspective. Zetischrift für Gerontologie \& Geriatrie, 41(4), 261-266.

Hughes, G., Bennett, K. M., \& Hetherington, M. M. (2004). Old and alone: barriers to healthy eating in older men living on their own. Appetite, 43(3), 269-276. http://dx.doi.org/10.1016/j.appet.2004.06.002

Inelmen, E. M., Gimenez, G. F., Gatto, M. R., Miotto, F., Sergi, G., Marccari, T., et al. (2000). Dietary intake and nutritional status in Italian elderly subjects. J Nutr Health Aging, 4(2), 91-101.

Johansson, L., Sidenvall, B., Malmberg, B., \& Christensson, L. (2009). Who will become malnourished? A prospective study of factors associated with malnutrition in older persons living at home. The Journal of Nutrition, Health \& Aging, 13(10), 855-861. http://dx.doi.org/10.1007/s12603-009-0242-3

Johansson, Y., Bachrach-Lindstrom, M., Carstensen, J., \& Ek, A. C. (2009). Malnutrition in a home-living older population: prevalence, incidence and risk factors. A prospective study. Jornal of Clinical Nursing, 18(9), 1354-1364. http://dx.doi.org/10.1111/j.1365-2702.2008.02552.x

Kallio, M. K., Koskinen, S. V., \& Prattala, R. S. (2008). Functional disabilities do not prevent the elderly in Finland from eating regular meals. Appetite, 51(1), 97-103. http://dx.doi.org/10.1016/j.appet.2007.12.006

Krassie, J., \& Smart, C. (2000). A Review of the nutritional needs of Meals on Wheels consumers and factors associated with the provision of an effective Meals on Wheels service - an Australian perspective. European Journal of Clinical Nutrition, 54(4), 275. http://dx.doi.org/10.1038/sj.ejcn.1600790

Kvale, S. (2007). Doing interviews: Sage.

Leppänen, V. (2008). Coping with troublesome clients in home care. Qualitative Health Research, 18(9), 1195. http://dx.doi.org/10.1177/1049732308321739

Lincoln, Y. S., \& Guba, E. G. (1985). Naturalistic inquiry: Sage.

Locher, J. L., Ritchie, C. S., Roth, D. L., Baker, P. S., Bodner, E. V., \& Allman, R. M. (2005). Social isolation, support, and capital and nutritional risk in an older sample: ethnic and gender differences. Social Sciences Medicin, 60(4), 747-761. http://dx.doi.org/10.1016/j.socscimed.2004.06.023 
Maynard, M., Gunnell, D., Ness, A. R., Abraham, L., Bates, C. J., \& Blane, D. (2006). What influences diet in early old age? Prospective and cross-sectional analyses of the Boyd Orr cohort. European Journal of Public Health, 16(3), 316-324. http://dx.doi.org/10.1093/eurpub/cki167

McKie, L., Clark, G. M., MacLellan, M., \& Skerratt, S. (1998). The promotion of healthy eating: food availability and choice in Scottish island communities. Health Education Research, 13(3), 371-382. http://dx.doi.org/10.1093/her/13.3.371

McKie, L., MacInnes, A., Hendry, J., Donald, S., \& Peace, H. (2000). The food consumption patterns and perceptions of dietary advice of older people. Journal of Human Nutrition and Dietetetics, 13(3), 173-183. http://dx.doi.org/10.1046/j.1365-277x.2000.00226.x

Meinow, B., Kåreholt, I., \& Lagergren, M. (2005). According to need? Predicting the amount of municipal home help allocated to elderly recipients in an urban area of Sweden. Health \& Social Care in the Community, 13(4), 366-377. http://dx.doi.org/10.1111/j.1365-2524.2005.00570.x

Meleis, A. I. (2010). Transitions theory: middle range and situation specific theories in nursing research and practice. New York: Springer

Meyer, J. E. (1993). New paradigm research in practice: the trials and tribulations of action research. $J$ Adv Nurs, 18(7), 1066-1072. http://dx.doi.org/10.1046/j.1365-2648.1993.18071066.x

Michaud, C., Baudier, F., Loundou, A., Le Bihan, G., Janvrin, M. P., \& Rotily, M. (1998). [Food habits, consumption, and knowledge of a low-income French population]. Sante Publique, 10(3), 333-347.

Nakura, I., Tatara, K., Shinsho, F., Fukuda, H., \& Nakajima, K. (1994). Demand by the elderly for "meals-on-wheels" services. Japanese Journal Of Public Health, 41(3), 253-261.

Odencrants, S., Ehnfors, M., \& Grobe, S. J. (2005). Living with chronic obstructive pulmonary disease: part I. Struggling with meal-related situations: experiences among persons with COPD. Scandinavian Journal of Caring Sciences, 19(3), 230-239. http://dx.doi.org/10.1111/j.1471-6712.2005.00345.x

Payette, H., Boutier, V., Coulombe, C., \& Gray-Donald, K. (2002). Benefits of nutritional supplementation in free-living, frail, undernourished elderly people: a prospective randomized community trial. J Am Diet Assoc, 102(8), 1088-1095. http://dx.doi.org/10.1016/S0002-8223(02)80077-3

Raadu, G. (2011). Statute handbook for personnel in health and care 2011 (in Swedish: Författningshandbok för personal inom hälso- och sjukvården. 2011). Stockholm: Liber.

Roberts, K. C., Wolfson, C., \& Payette, H. (2007). Predictors of nutritional risk in community-dwelling seniors. Can J Public Health, 98(4), 331-336.

Rochat, S., Cumming, R. G., Blyth, F., Creasey, H., Handelsman, D., Le Couteur, D. G., et al. (2010). Frailty and use of health and community services by community-dwelling older men: the Concord Health and Ageing in Men Project. Age Ageing, 39(2), 228-233. http://dx.doi.org/10.1093/ageing/afp257

Rothenberg, E., \& Lewald, B. (2006). Näringslära : en kunskaps- och inspirationskälla från Recip. Årsta: Recip.

Saif, M. (2000). World Medical Association Declaration of Helsinki: ethical principles for medical research involving human subjects. Jama, 284, 3043-3045. http://dx.doi.org/10.1001/jama.284.23.3043

Statistical Central Office. (2009). The Swedish future population 2009-2060 (in Swedish: Sveriges framtida befolkning 2009-2060). Stockholm: Stockholm: Statistical Central Office (in Swedish: Statistiska centralbyrån, $\mathrm{SCB})$.

Sidenvall, B. (1995). The meal in geriatric care : habits, values and culture. Linköping: Univ.

Sidenvall, B. (1997). Mealtimes in geriatrics: meetings with variuos meal patterns and lost of habitual meal behaviours (in Swedish: Måltiden inom geriatriken, möten med olika måltidsvanor och förlust av invant måltidsbeteende). Lund: HSF.

Sidenvall, B., Fjellstrom, C., \& Ek, A. C. (1994). The meal situation in geriatric care - intentions and experiences. Journal of Advanced Nursing, 20(4), 613-621. http://dx.doi.org/10.1046/j.1365-2648.1994.20040613.x

Sneeuw, K. C., Stam, P. G., de Graaf, C., \& van Staveren, W. A. (1991). Home food services for the elderly: the consumer and his appreciation of a warm meal service in Arnhem. Tijdschrift Voor Gerontologie En Geriatrie, 22(1), 29-33.

Sobal, J., \& Nelson, M. K. (2003). Commensal eating patterns: a community study. Appetite, 41(2), 181-190. http://dx.doi.org/10.1016/S0195-6663(03)00078-3 
Stringer, E. T., \& Genat, W. J. (2004). Action research in health. Upper Saddle River, N.J.: Merrill Prentice Hall. Timonen, V., \& O'Dwyer, C. (2010). 'It is nice to see someone coming in': exploring the social objectives of Meals-on-Wheels. Canadian Journal of Aging, 29(3), 399-410. http://dx.doi.org/10.1017/S0714980810000371

Walker, D., \& Beauchene, R. E. (1991). The relationship of loneliness, social isolation, and physical health to dietary adequacy of independently living elderly. Journal of American Dietetic Assocation, 91(3), 300-304.

Ångren, B. (2003). Chain of care development in Sweden: results of a national study. International Journal of Integrated Care, Oct 7;3:e1. 